\title{
ASSESSMENT OF SUPPLY CHAIN MANAGEMENT MATURITY
}

\begin{abstract}
Maturity models are used to diagnose and identify opportunities to improve Supply Chain Management (SCM) from immature to mature processes, through best practices. This paper contributes by proposing an assessment of SCM maturity that includes the Analytic Hierarchy Process (AHP) and concepts from SCM maturity literature. This assessment was applied in a global chemical company, which allowed capturing the level of SCM maturity for three business units. The results revealed that there are opportunities to improve the SCM maturity for Unit A (upgrading from Level 4 to Level 5) and Units B and C (assessed as in Level 3 of SCM maturity).
\end{abstract}

Keywords: analytic hierarchy process, supply chain management, maturity model.

\section{Introduction}

Maturity models appeared in Quality Management (Estampe et al., 2013). A well-known maturity model derived from the Quality Management approach is the Capability Maturity Model (CMM) developed at Carnegie Mellon University (Wendler, 2012). CMM provides a diagnosis to describe the path of improvement from immature to mature processes, defining maturity levels. Supply Chain Management (SCM) maturity models result in SCM assessment, identifying gaps and opportunities for processes improvement through best practices (Netland and Alfines, 2011). Therefore, our main objective was to assess the SCM maturity. The paper includes the application of the Analytic Hierarchy Process (AHP) in a global chemical company, assessing SCM maturity at three business units.

\section{Literature Review}

Maturity models are often explained in two dimensions that involve levels of maturity and best practices (Souza et al., 2012). Oliveira et al. (2012) propose Supply Chain Process Management Maturity Model (SCPM3), as a method related to the assessment and control of business processes. SCPM 3 has five levels: Foundation, Structure, Vision, Integration and Dynamics.

An AHP application consists of a few steps, including hierarchy construction, pairwise comparison, consistency verification, and results. Furthermore, there is a possibility of using ratings or absolute measure in the AHP application. In ratings, each alternative is compared with an ideal one (Saaty, 2006).

\section{AHP applied in supply chain management maturity assessment}

The research presented in this work was conducted in chemical company located in Sao Paulo, Brazil. This plant belongs to a multinational group acting in 170 countries, with direct production in 40 countries. Here we applied the AHP to assess the SCM maturity assessment, and we compared its results with the results obtained by the traditional method 
ISAHP Article: Author 1, Author 2, Author 3/Assessment of supply chain management maturity International Symposium of the Analytic Hierarchy Process 2016, London, U.K.

SCPM3. The goal of the proposed AHP model was to "Assess SCM maturity" and the identification of the set of criteria was "level 1, level 2, level 3, level 4 and level 5". Figure 1 presents the incomplete AHP hierarchical structure adopted in this work.

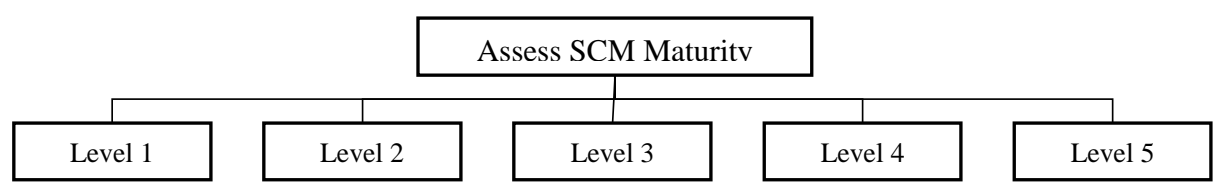

Figure 1. Hierarchy model for SCM maturity assessment

We adopted the AHP ratings for doing an alternative assessment of maturity level for three business units (A, B and C) of the studied chemical company (Table 1), and the results are in Table 2. The SCPM3 model, containing 89 questions items was also applied. Experts should specify (1 to 5) and their level of agreement or disagreement, provided maturity levels for the same three business units as illustrated in Table 2. Observe that the experts who took part in both assessments were SCM managers from the three company's business areas $\mathrm{A}, \mathrm{B}$ and $\mathrm{C}$.

Table 1. Priorities of maturity levels

\begin{tabular}{c|c|c|c|c|c|c}
\hline & Level 5 & Level 4 & Level 3 & Level 2 & Level 1 & Priority \\
\hline Level 5 & 1 & 2 & 3 & 5 & 7 & 1 \\
\hline Level 4 & & 1 & 3 & 3 & 7 & 0.7 \\
\hline Level 3 & & & 1 & 2 & 5 & 0.4 \\
\hline Level 2 & & & & 1 & 5 & 0.2 \\
\hline Level 1 & & & & & 1 & 0.1 \\
\hline
\end{tabular}

In Table 2 the results of assessment of the business areas indicated no differences on maturity levels for SCPM3 and AHP evaluation.

Table 2. Maturity assessment

\begin{tabular}{c|c|c|c|c}
\hline Business Unit & $\begin{array}{c}\text { SCPM3 } \\
\text { (Score) }\end{array}$ & $\begin{array}{c}\text { SCPM3 } \\
\text { (Level) }\end{array}$ & $\begin{array}{c}\text { AHP } \\
\text { (Ratings) }\end{array}$ & $\begin{array}{c}\text { AHP } \\
\text { (Level) }\end{array}$ \\
\hline A & 324 & 4 & 0.72 & 4 \\
\hline B & 292 & 3 & 0.65 & 3 \\
\hline C & 275 & 3 & 0.62 & 3 \\
\hline
\end{tabular}

\section{Conclusions}

Results revealed that there is an opportunity to improvement the SCM maturity of business unit A from Integration (Level 4) to Dynamics (Level 5). Business Units B and C must focus Vision (Level 3) and Integration (Level 5) issues. In conclusion, by means a real application, it was illustrated how AHP can be applied to assess SCM maturity. New researches maybe developed from the exposed, considering, as example, dependency between two alternatives. This way, ANP shall be applied.

\section{Key References}

Due to the two-page limit, reference list can be obtained from authors, upon request. 